\title{
On the possible role of cusp/cleft precipitation in the formation of polar-cap patches
}

\author{
I. K. Walker ${ }^{1}$, J. Moen ${ }^{2,3}$, L. Kersley ${ }^{1}$, D. A. Lorentzen ${ }^{4}$ \\ ${ }^{1}$ Department of Physics, University of Wales, Aberystwyth, Ceredigion, SY23 3BZ, UK \\ E-mail: lek@aber.ac.uk \\ ${ }^{2}$ AFRL/VSB (Space), Hanscom AFB, MA 01731, USA \\ ${ }^{3}$ On sabbatical leave from Arctic Geophysics, University Courses on Svalbard, N-9170, Longyearbyen, Norway \\ ${ }^{4}$ Arctic Geophysics, University Courses on Svalbard, N-9170, Longyearbyen, Norway
}

Received: 23 February 1999 / Revised: 7 May 1999 / Accepted: 17 May 1999

\begin{abstract}
The work describes experimental observations of enhancements in the electron density of the ionospheric F-region created by cusp/cleft particle precipitation at the dayside entry to the polar-cap convection flow. Measurements by meridian scanning photometer and all-sky camera of optical red-line emissions from aurora are used to identify latitudinally narrow bands of soft-particle precipitation responsible for structured enhancements in electron density determined from images obtained by radio tomography. Two examples are discussed in which the electron density features with size scales and magnitudes commensurate with those of patches are shown to be formed by precipitation at the entry region to the anti-sunward flow. In one case the spectrum of the incoming particles results in ionisation being created, for the most part below $250 \mathrm{~km}$, so that the patch will persist only for minutes after convecting away from the auroral source region. However in a second example, at a time when the plasma density of the solar wind was particularly high, a substantial part of the particle-induced enhancement formed above $250 \mathrm{~km}$. It is suggested that, with the reduced recombination loss in the upper F-region, this structure will retain form as a patch during passage in the anti-sunward flow across the polar cap.
\end{abstract}

Key words. Ionosphere (ionospheric irregularities; particle precipitation; polar ionosphere)

\section{Introduction}

Structures of enhanced F-region density at a variety of scale sizes are present in the polar-cap ionosphere. One class of features, commonly referred to as polar-cap patches, appear in the form of localised regions of

Correspondence to: L. Kersley enhanced F-region plasma density, drifting in the antisunward convection across the polar cap (Buchau et al., 1983; Weber et al., 1984, 1986). The patches were identified using ionosodes and all-sky imaging photometers, but subsequently have been studied by many other instrumental techniques, including incoherent scatter radar, HF radar and even radio scintillation. A comprehensive review by Crowley (1996) gives an excellent overview of current understanding of polar-cap patch morphology and formation. Comparison between different techniques is not always easy because of different criteria used to define patches. However Crowley (1996) reports an attempt to give formal definition, where plasma enhancements observed by radio techniques should only be called patches if they are at least a factor of two above the background density and at least $100 \mathrm{~km}$ in diameter. For observations of $630.0 \mathrm{~nm}$ airglow due to radiative recombination of $\mathrm{O}^{+}$, a patch should be at least $50 \mathrm{R}$ and more than $50 \%$ above the background brightness.

Polar-cap patches occur predominantly under active conditions when the $B_{z}$ component of the interplanetary magnetic field (IMF) has a southward component (Buchau et al., 1983; McEwan and Harris, 1996). However, no single mechanism has been identified as being responsible for the creation of patches. Most of the proposed mechanisms rely on plasma transport, rather than in-situ production, and almost all of the reported experimental evidence is in the form of individual case studies. Several authors, including Foster and Doupnik (1984), Kelley and Vickrey (1984), Whalen (1994) and Pinnock et al. (1995), reported regions of enhanced F-layer plasma convecting from the solar-illuminated dayside into the cusp/throat region. Buchau et al. (1985) found that the electron densities in the patches were similar to those at dayside sub-auroral latitudes, leading to proposed production mechanisms whereby solar-produced plasma becomes entrained in the high-latitude convection system, feeding a 'tongue-of-ionisation' into the polar cap. It has been suggested that time-varying changes to the convection 
pattern segment the tongue of ionisation and hence generate patches. Variations in both the $B_{z}$ and $B_{y}$ components of the IMF have been cited as being responsible for the plasma structuring. Several modellers have demonstrated that simple, instantaneous switches in the IMF could result in discrete patches similar to those observed experimentally (e.g., Anderson et al., 1988; Sojka et al., 1993, 1994; Decker et al., 1994). The transient reconnection associated with flux transfer events has been invoked by Lockwood and Carlson (1992) as a possible mechanism. However, it has been noted that typical latitudinal gradients in electron density may not be sufficient to explain patch formation by rapid changes in the IMF; a problem particularly acute in the Southern Hemisphere, where the terminator often lies well away from the convection throat (Rodger et al., 1994). Other possible causes for break-up of the tongue of ionisation include more localised convection effects, like short-lived convection jets linked to flow-channel events (Rodger et al., 1994) and travelling twin-convection vortices (Schunk et al., 1994). The highspeed plasma flows associated with such phenomena generate localised Joule heating, with a rise in plasma temperature leading to an enhanced ion-recombination rate (Valladares et al., 1996). It is suggested that the localised erosion of the plasma density causes segmentation of the tongue of ionisation into discrete patches. Additional sources of plasma enhancement have been considered, including in-situ production by particle precipitation. Weber et al. (1984) proposed the idea of 'spatial resonance', in which plasma and particle source convect together at the same velocity, thus allowing sufficient time for the plasma density to build-up. More recent work by Rodger et al. (1994) cites a combination of particle precipitation in the cusp coupled with flowchannel events to explain two case studies of patch formation over Antarctica. However, little work has been done to ascertain the possible contribution of particle precipitation to patch formation and there have been few experimental observations.

The current study addresses the issue of particleimpact ionisation associated with cusp/cleft precipitation. The spatial distribution of ionospheric plasma density near the polar-cap inflow region has been obtained by radio tomography above Svalbard. Two contrasting examples are reported in which structures in electron density are identified in the source region that have the characteristics of patches. In the first the particle-induced ionisation is situated mainly below $250 \mathrm{~km}$, where the recombination rate is high, and is thus unlikely to be particularly long lived. The second example is characterised by a considerably higher flux of softer particles, resulting in substantial ionisation above $250 \mathrm{~km}$, with the formation of a patch that has the potential to retain form in the convective flow across the polar-cap.

\section{Instrumentation}

The optical instruments used were a meridian scanning photometer (MSP) and an all-sky camera at the Auroral
Station, Longyearbyen $\left(78.2^{\circ} \mathrm{N}, 15.3^{\circ} \mathrm{E}\right)$. The MSP consists of a parallel assembly of six photomultiplier tubes, each with a tilting narrow-band interference filter to allow subtraction of background light from the peak emission (Romick, 1976). A mirror in front of the tubes scans essentially along the magnetic meridian from north to south ( $45^{\circ}$ west of geographic north). A full meridian scan, with the background subtracted, is obtained every $16 \mathrm{~s}$. Observations from two of the emission lines monitored by the instrument have been used here: the red $(630.0 \mathrm{~nm})$ and green $(557.7 \mathrm{~nm})$ wavelengths emitted by atomic oxygen, which are both stimulated by particle precipitation. The all-sky camera was filtered at $630.0 \mathrm{~nm}$ and provided an image every $20 \mathrm{~s}$.

The radio tomography monitoring system comprises receivers at $\mathrm{Ny}$ Ålesund $\left(78.9^{\circ} \mathrm{N}, 12.0^{\circ} \mathrm{E}\right)$, Longyearbyen $\left(78.2^{\circ} \mathrm{N}, 15.3^{\circ} \mathrm{E}\right)$, Bjørnøya $\left(74.5^{\circ} \mathrm{N}, 19.0^{\circ} \mathrm{E}\right)$ and Trom$\mathrm{s} \varnothing\left(69.8^{\circ} \mathrm{N}, 19.0^{\circ} \mathrm{E}\right)$. Measurements are made of total electron content using signals from satellites in the Navy Ionospheric Monitoring System (NIMS). The observations are then inverted in a reconstruction algorithm to create spatial images of electron density as a function of height and latitude. A fuller description of experimental ionospheric tomography can be found in Walker et al. (1996).

\section{Observations}

Two examples are described illustrating contrasting aspects of the influence of cusp/cleft precipitation on ionospheric electron density. Observations made on 14 December, 1996, were first reported by Walker et al. (1998) and interpreted in terms of the ionospheric effects of magnetopause reconnection. Figure 1 shows records from both the red- and green-channels of the MSP between 10:41 UT and 10:49 UT. There is clear evidence of auroral activity, with a sharply defined equatorward boundary lying to the south of Longyearbyen. The maximum peak intensity observed for the red-line was some $12.5 \mathrm{kR}$, with an average peak intensity of about $9 \mathrm{kR}$ for the 30 scans made during this interval. The average ratio between the red- and green-line intensities was 4.9. There is some evidence for finer structure within the main band of the $630 \mathrm{~nm}$ emission and rebrightening of the auroral features. It must, of course, be emphasised that the red-line observations studied here are of intense auroral emissions, in contrast to the weak airglow used for many studies of patches in the polar cap.

The tomographic image in Fig. 2 shows the distribution of electron density as a function of height and latitude, obtained from a southward heading satellite pass that crossed $78^{\circ} \mathrm{N}$ latitude at 10:46 UT. The main feature of interest to the current study is the F-region density enhancement between about $77.5^{\circ}$ and $79^{\circ} \mathrm{N}$. It can be seen that the structure is bounded at its equatorward edge by a sharp gradient in density to the south of Longyearbyen, identified by Walker et al. (1998) as a signature of the open/closed field-line 
$630.0 \mathrm{~nm}$

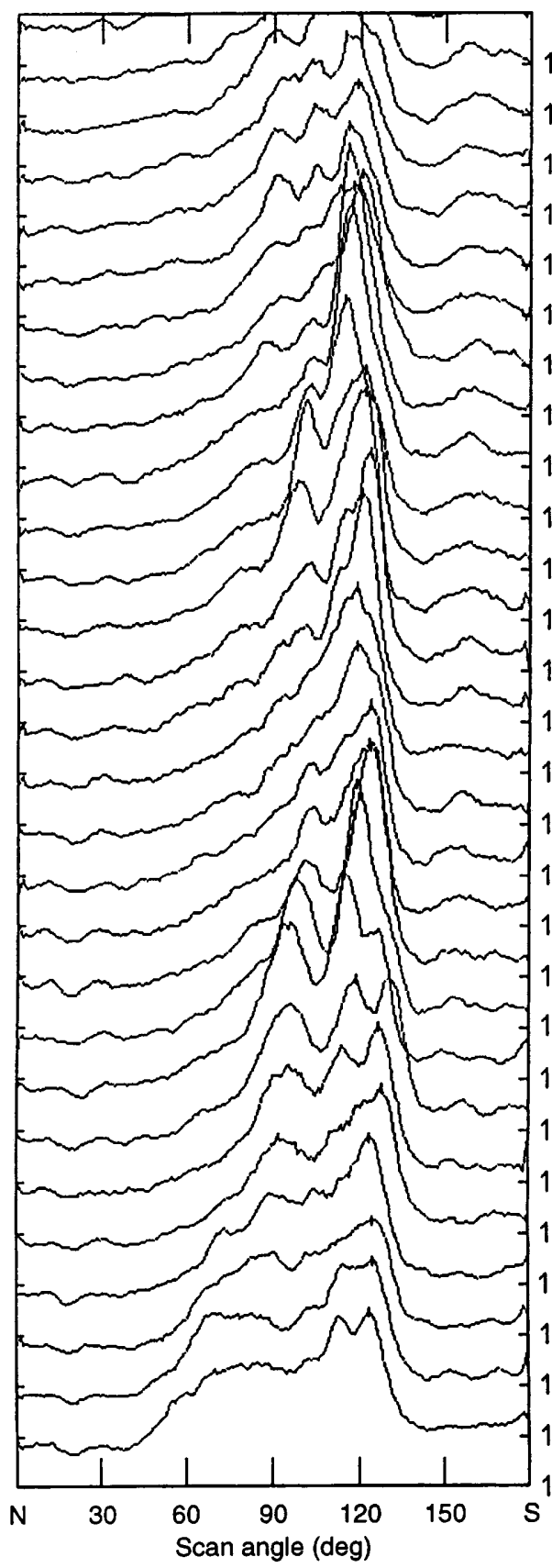

Time (UT)

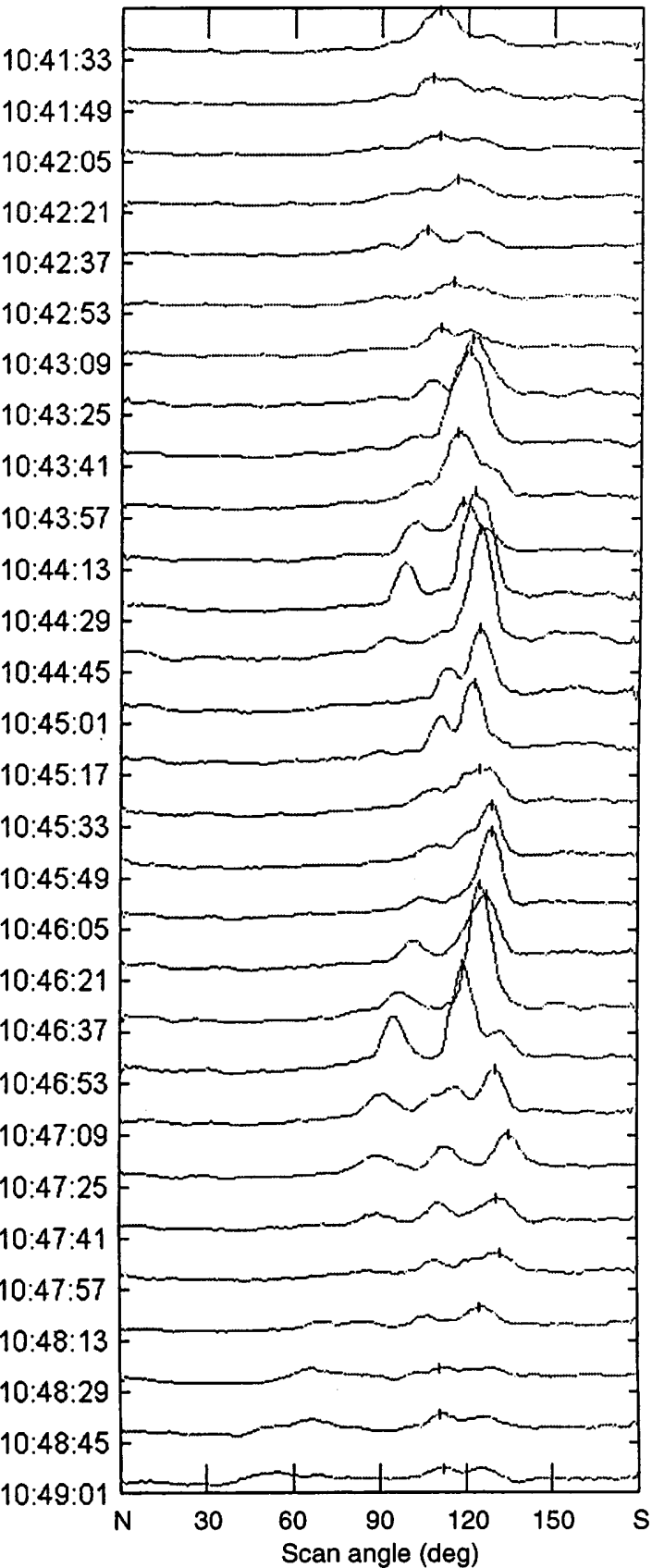

$557.7 \mathrm{~nm}$
Fig. 1. Stacked plot of intensities of red $(630.0 \mathrm{~nm})$ and green $(557.7 \mathrm{~nm})$ emissions measured by the meridian scanning photometer between 1041 UT and 1049 UT on 14 December, 1996 boundary. The location of this boundary and the latitudinal extent of the feature are consistent with the band of $630 \mathrm{~nm}$ aurora seen in Fig. 1. The peak electron density is in excess of $2.75 \times 10^{11} \mathrm{~m}^{-3}$ and the structure contains two, possibly three, localised enhancements. The peak height is below $200 \mathrm{~km}$ at $77.5^{\circ} \mathrm{N}$ rising to approach $240 \mathrm{~km}$ at $79^{\circ} \mathrm{N}$. It can be noted for later comparison that the $2 \times 10^{11} \mathrm{~m}^{-3}$ contour on the topside is at about the $250 \mathrm{~km}$ altitude level. Furthermore, the peak density in the enhanced region is almost an order of magnitude greater than that of the background ionisation just outside the polar cap in the trough to the south.
Measurements by the WIND spacecraft provide information about the IMF. The formula of Lockwood et al. (1989), for the time delay between the satellite measurements and the corresponding ionospheric response, gives a lag of some $27 \mathrm{~min}$ in this case. During the period of interest, $B_{z}$ was established negative at about $-3 \mathrm{nT}$, while $B_{y}$ was around $+2 \mathrm{nT}$ and the plasma ion density of the solar wind was about $6 \mathrm{~cm}^{-3}$.

The second example comes from observations made on the 10 December, 1997. Figure 3 shows the measurements from the red- and green-line channels of the MSP between 08:32 UT and 08:40 UT. The maximum peak intensity in the red-line was almost $27.5 \mathrm{kR}$, while 


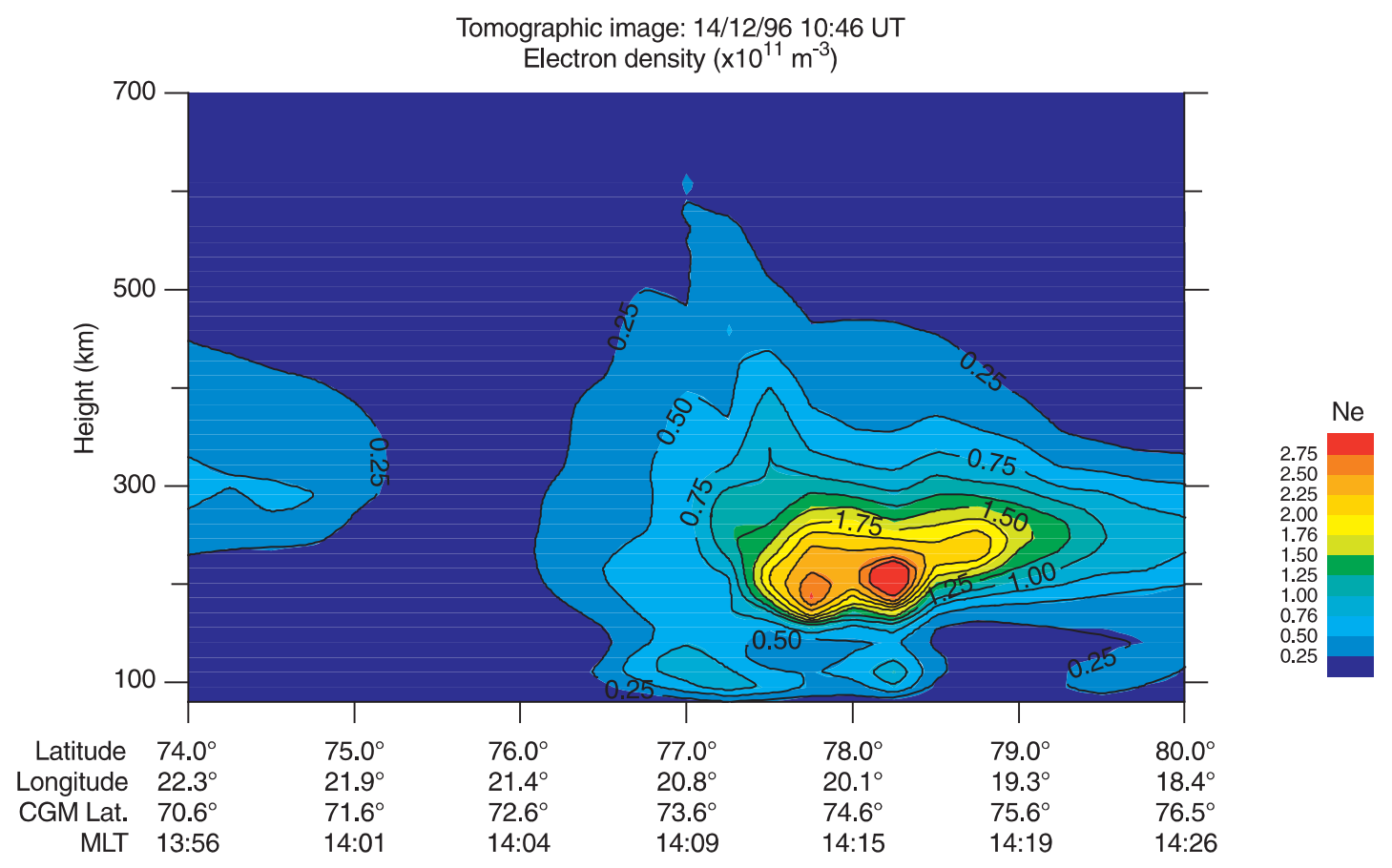

Fig. 2. Tomographic images of electron densities obtained from a satellite pass that crossed $78^{\circ} \mathrm{N}$ at 1046 UT on 14 December, 1996

the average peak intensity for the 30 scans during the interval was about $18.5 \mathrm{kR}$. The average red- to greenline intensity ratio was 8.6 .

The tomographic image in Fig. 4 shows the electron density as a function of height and latitude, obtained from a southward satellite pass that crossed $78^{\circ} \mathrm{N}$ at 08:38 UT. The F-region in the north of the image exhibits clear structuring, with a feature that is contiguous with the red auroral emissions and containing two localised density enhancements between about $78^{\circ} \mathrm{N}$ and approximately $80.5^{\circ} \mathrm{N}$. The peak densities, in excess of $4.5 \times 10^{11} \mathrm{~m}^{-3}$, are significantly larger than those observed in the image described earlier (Fig. 2) and, in the current example, the topside $2 \times 10^{11} \mathrm{~m}^{-3}$ contour is generally above $325 \mathrm{~km}$ in the structure. The layer peak is at a height of around $250 \mathrm{~km}$, with a density greater by a factor of almost five in comparison with that found in the trough to the south.

A broader picture of the $630.0 \mathrm{~nm}$ auroral activity at the appropriate time on 10 December, 1997 is presented in Fig. 5. This shows three images from the all-sky camera separated by 2 min intervals. The sub-ionospheric track of the NIMS satellite has been included in each panel. It can be seen that the red-line activity forms a narrow latitudinal band over Svalbard though with a broadening of the structure to the east. Fuller examination of the all-sky images showed that the cusp activity centre, with quasi-periodic intensifications, was located east of Svalbard. The NIMS satellite intersected one event in a sequence of intensifications.

IMF data from the WIND spacecraft, with an appropriate lag of some $75 \mathrm{~min}$ in this case, show that $B_{z}$ was again established southwards with a value of about $-3 \mathrm{nT}$, while $B_{y}$ fluctuated around $-13 \mathrm{nT}$.
Significantly, the plasma density was about $33 \mathrm{~cm}^{-3}$, more than five times larger than in the previous example.

\section{Discussion}

According to the classification scheme of dayside auroral activity given by Sandholt et al. (1998), the two cases presented here both belong to type 1 cusp aurora. Type 1 includes the classical sequences of moving auroral forms, which dominate the cusp/cleft activity picture under conditions of southward IMF. The event recurrence period for this activity is typically 5 to $10 \mathrm{~min}$, and the movement of type 1 auroral forms has been found to follow the ionospheric convection pattern which is IMF controlled (Sandholt et al., 1993, 1998; Moen et al., 1995, 1999). This class of activity is widely accepted as a candidate footprint of time-varying reconnection at the dayside magnetopause (Lockwood et al., 1998). The pulsed nature of cusp auroral activity indicates that ionospheric plasma, drifting into the polar cap through the cusp inflow region, is exposed to pulsed showers of magnetosheath particle precipitation.

The co-location of enhancements in ionospheric electron density with auroral activity implies that particle precipitation has played a direct role in the creation of the elevated densities (Moen et al., 1998; Berry et al., submitted 1999). While a consistent picture emerges from the two data sets, the red-line intensities observed on 10 December, 1997, were more than double those of 14 December, 1996. Similarly, the red-to-green intensity ratio was significantly enhanced in the 1997 case, implying a greater bias towards lower energy 


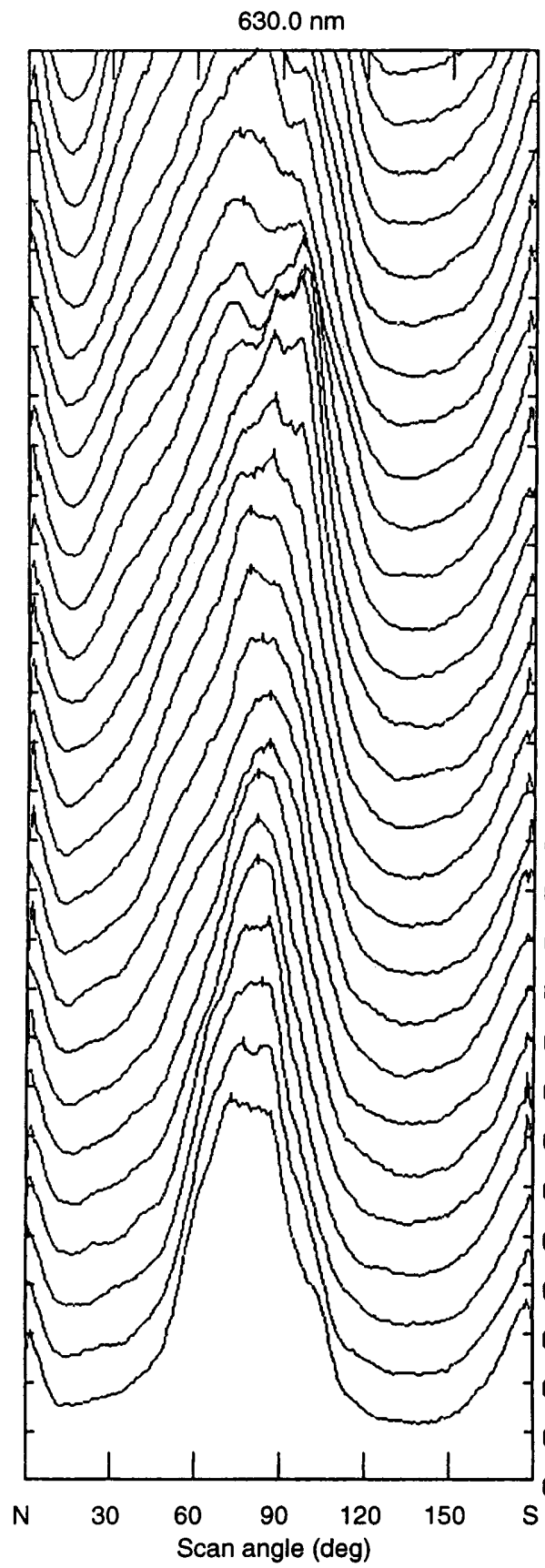

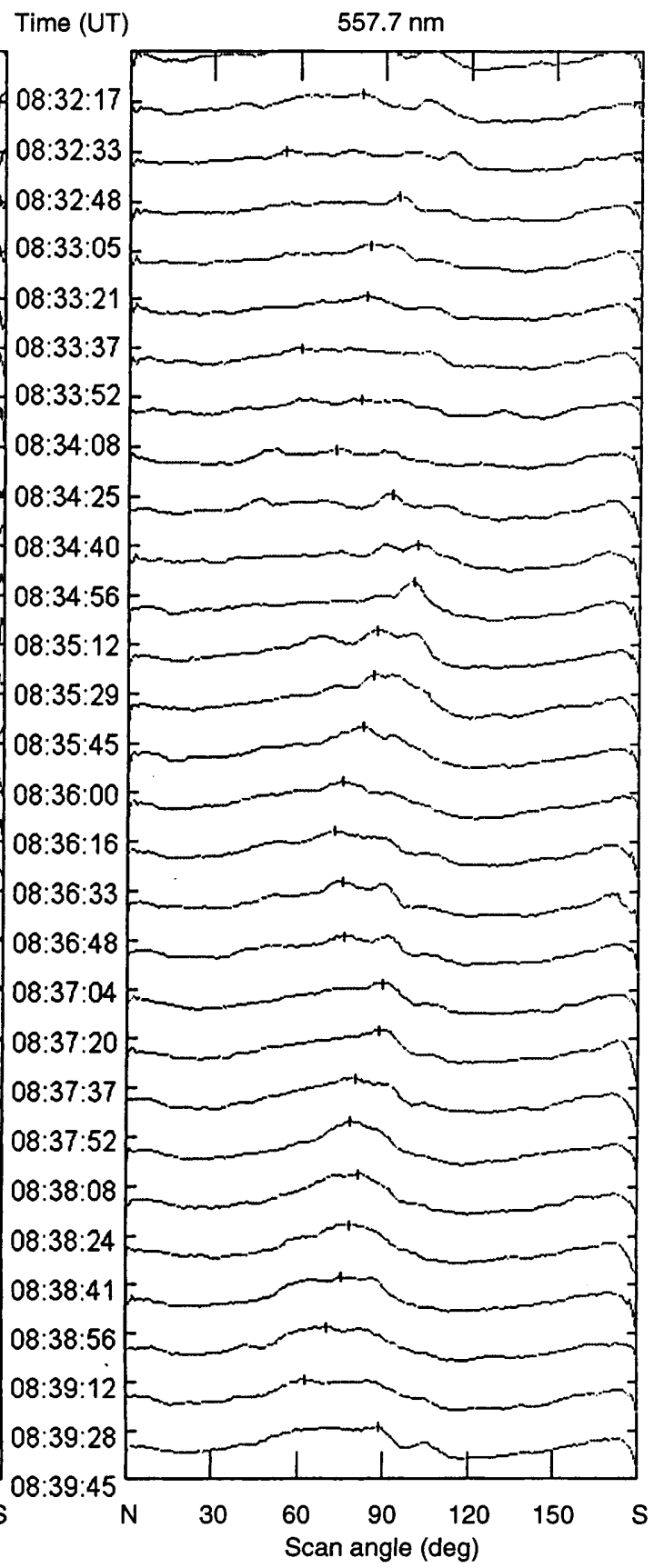

Fig. 3. Stacked plot of intensities of red $(630.0 \mathrm{~nm})$ and green $(557.7 \mathrm{~nm})$ emissions measured by the meridian scanning photometer between 0832 UT and 0840 UT on 10 December, 1997 ionising particles in the incoming spectrum. The spectral distribution, coupled with the significantly larger solar wind plasma densities on 10 December, 1997, suggest that the incoming particle flux was more likely to result in enhanced electron densities at higher altitude on that day than in the earlier example. This conclusion is confirmed by the tomographic images of electron density distribution, which show that the layer is at a higher altitude and with peak densities some $60 \%$ greater than in the example from 1997. In addition, there is clear evidence of enhanced levels of ionisation extending into the topside. The all-sky camera results confirm that the aurora, and hence the precipitation source for the ionospheric enhancement, is confined to a limited band of a few degrees latitude, consistent with the tomographic observations and with the accepted scale size of polar-cap patches. It should be noted that whilst the plane of the tomographic image is closer than the photometer scan to the cusp activity centre, the allsky imager data reveals that both intersect regions exhibiting auroral phenomena typical of cusp dynamics. Extended observations from the all-sky camera also confirm the pulsating nature of the red-line aurora in this case even though this is not immediately apparent from Fig. 3. Furthermore, inspection of the green-line data recorded by the imager demonstrates the red-line dominance over the green aurora for the entire field of view.

Given the prevalent IMF conditions, with a southward $B_{z}$ in both cases, it seems likely a two-cell 


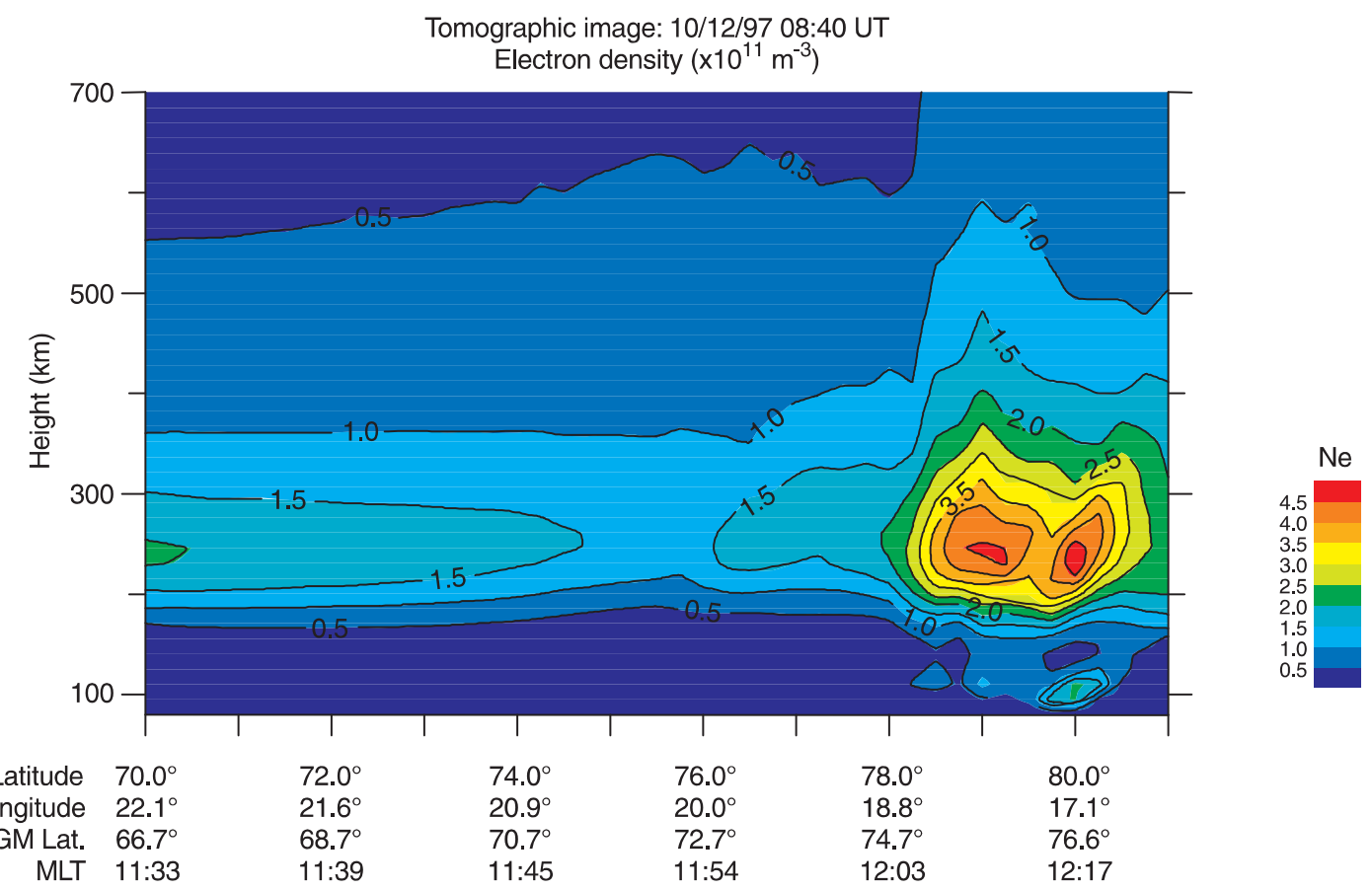

Fig. 4. Tomographic images of electron densities obtained from a satellite pass that crossed $78^{\circ} \mathrm{N}$ at 0840 UT on 10 December, 1997

convection pattern was established at the times of observation, with anti-sunward flow into the polar cap. Thus, it is reasonable to assume that in both cases the plasma enhancements formed by the precipitation will move with the background convection and eventually be carried across the polar cap. It should be noted, however, that release of the magnetic stress dominates the initial motion of a newly opened field line and when $B_{y}$ is non-zero the plasma motion will have a zonal component. As tension is released and the line unbends the pull of the solar wind takes over. Given the dominance of $B_{y}$ negative in the second example, the initial plasma motion will probably be eastward before the pull of the solar wind eventually brings the plasma into the polar cap outside the plane of the tomographic image. This view is supported by the all-sky measurements which show pulsed red-line emissions moving eastward. It is thus possible that initial flow along the L-shells keeps the plasma in the source region allowing the densities to build up.

In addition to transport, consideration must also be given to the lifetime of the F-region plasma. $\mathrm{O}^{+}$is the

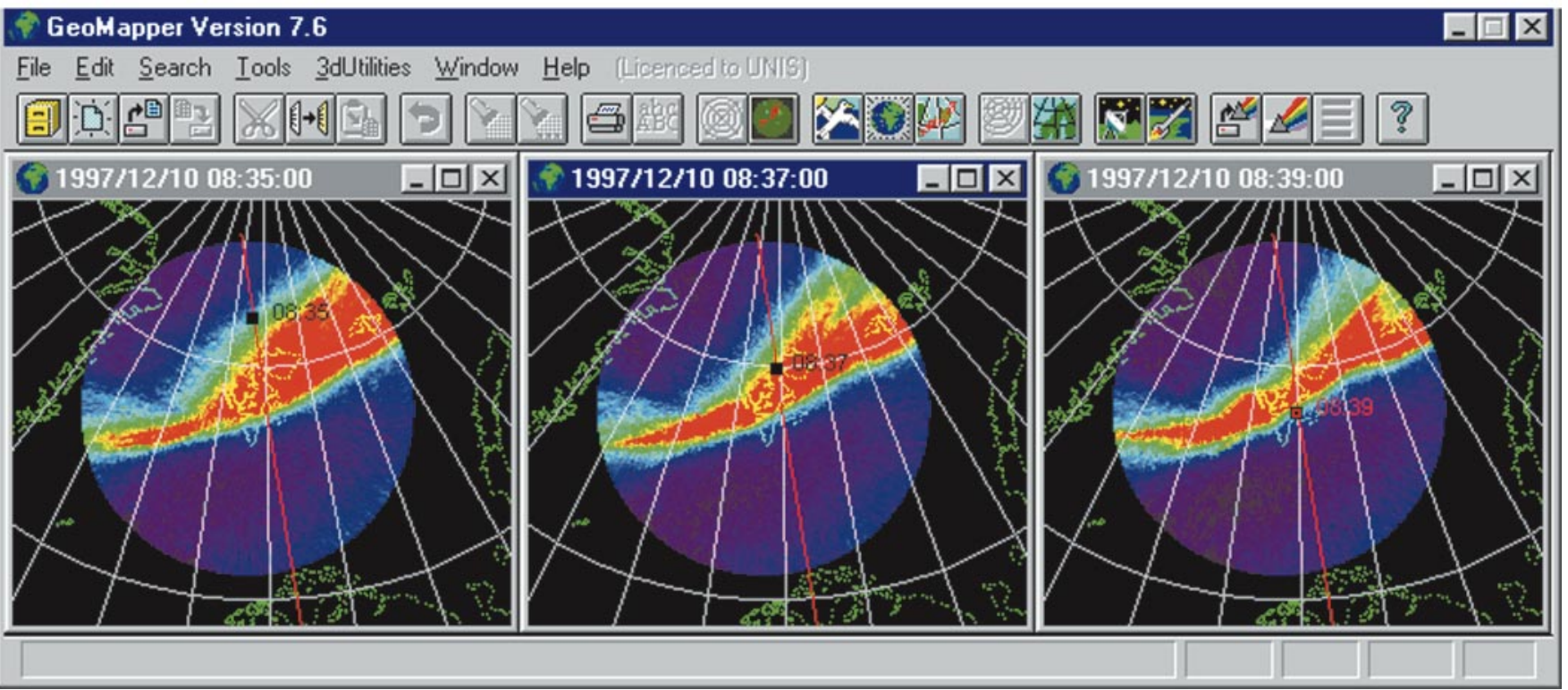

Fig. 5. A succession of false-colour images of red-line intensity obtained from the all-sky camera between 0835 UT and 0840 UT on 10 December, 1997 
primary ion constituent above $250 \mathrm{~km}$. The dominant mechanisms of chemical loss of $\mathrm{O}^{+}$is through slow ionmolecule reactions with $\mathrm{N}_{2}$ and $\mathrm{O}_{2}$ to form $\mathrm{NO}^{+}$and $\mathrm{O}_{2}^{+}$, which in turn rapidly undergo dissociative recombination with electrons (Banks and Kockarts, 1973). Simple calculations have been made to estimate expected lifetimes. These have been based on the recombination rates given by Banks and Kockarts (1973), the MSIS-90 model for $\mathrm{N}_{2}$ and $\mathrm{O}_{2}$ density profiles versus height, and the measured electron densities. The decay time has been calculated for the F-region plasma enhancements to reach a density of $2 \times 10^{11} \mathrm{~m}^{-3}$; that is, still a factor two above the background level of $1 \times 10^{11} \mathrm{~m}^{-3}$. For the density feature on 10 December, 1997, the lifetime of the F-region structure was found to be $\sim 40 \mathrm{~s}$ at $200 \mathrm{~km}, \sim 10 \mathrm{~min}$ at $250 \mathrm{~km}$ and increasing to $\sim 1 \mathrm{~h}$ at $300 \mathrm{~km}$. Thus, it seems probable that this feature will be long-lived as it convects with the background plasma away from the region of particle precipitation and across the polar cap in the form of a patch. However, for the feature observed on the 14 December, 1996, most of the enhanced density was found below $250 \mathrm{~km}$ altitude and hence it will have a lifetime limited to minutes after convecting away from the region of particle precipitation.

The present study has shown that particle precipitation in the cusp/cleft region can be responsible for the creation of structures in electron density with magnitude, scale and transport consistent with the known characteristics of polar-cap patches. While limited information can be obtained from a case study it must be recalled that almost all of the other proposed patch mechanisms have their origins in case studies and little work has been possible to date on the difficult task of assessing the importance of the various candidate processes. However, the particular conditions prevalent in the present study can be examined. The observations on 10 December, 1997, were made on a day when the ion density of the solar wind measured by the WIND satellite was very large, exceeding that for the earlier example by a factor of about 5 . The $630 \mathrm{~nm}$ intensities measured on this day were typically doubled with respect to the earlier case, while the ratio of the redto-green emission intensity ratio was some $75 \%$ larger. Another important difference was that the 1997 case was observed near magnetic noon around 1150 MLT, while that in 1996 was observed postnoon around 1350 MLT; the auroral station at Longyearbyen crosses magnetic noon about 0850 UT. It is suggested that in the former case the reconnection is near the sub-solar point, while the latter example is a candidate for reconnection on the flanks. For reconnection on the flanks, the injected plasma has to swim against a substantial anti-sunward movement of the newly opened flux tube, so that the softest particles will not be able to penetrate down to the ionosphere, with a consequent hardening of the auroral spectrum. It appears likely that the density of the magnetosheath source plasma and the location of plasma injection (MLT-hours) are two critical parameters in determining whether or not cusp/cleft precipitation can lead to the creation of ionospheric plasma structures at sufficiently high altitudes to persist in the convective transport across the polar cap.

\section{Conclusion}

The combination of optics and radio tomography provides a new opportunity to study experimentally the ionisation impact of cusp precipitation in the Fregion ionosphere, and hence the possible role in patch formation. The two examples presented here demonstrate that precipitation of soft particles into the cusp/ cleft region can play a potential role in the formation of structures in electron density with the characteristics of polar-cap patches. Both cases show that the precipitation can create F-layer features, with horizontal extents of hundreds of kilometres containing sub-structuring on a finer scale, and densities significantly above background, to be carried in a convective flow into the polar cap. The lifetimes of such structures will be dependent on the spectrum of the precipitation and the consequent height of the ionisation created. In the first case presented here, most of the plasma was to be found below $250 \mathrm{~km}$ in a region where recombination will result in degradation on a timescale of less than $10 \mathrm{~min}$. Thus, while the structure might have been identified as a patch in the entry region it is unlikely that the form would have been preserved in the cross-polar convection. By contrast, in the other example, the spectrum of the precipitation resulted in the creation of ionisation above $250 \mathrm{~km}$ that may have been sufficiently long lived to survive transport across the polar cap while retaining the characteristics of a patch. The present study indicates that cusp/cleft particle precipitation alone may on occasion be capable of forming polar-cap patches. The solar wind density was unusually high on this particular day, and more cases have to be investigated before any decisive conclusion can be drawn on the relative importance of cusp particle precipitation compared to the other competing mechanisms.

Acknowledgements. The radio tomography experiment is funded by the UK Particle Physics and Astronomy Research Council (PPARC) under grant GR/K98787. Financial support has also been provided by the Norwegian Research Council, UNIS grant $9 /$ 963, and AFOSR task 2310G9. Thanks are due to the Norwegian Polar Research Institute at Ny Ålesund, staff at UNIS, Longyearbyen and Prof. T. Hansen and staff at the University of Tromsø for support for the tomographic observations. Data from the WIND satellite were provided by R. Lepping at NASA/GSFC. We are greatly appreciative of the support of Dr. R.W. Smith and his colleagues at the Geophysical Institute, University of Alaska, for the continuous operation of and the availability of data from the MSP. The authors also wish to thank Dr. H.C. Carlson for fruitful discussions in relation to this study.

The Editor in Chief thanks J.W. MacDougall and J.A. Whalen for their help in evaluating this paper.

\section{References}

Anderson, D. N., J. Buchau, and R. A. Heelis, Origin of density enhancements in the winter polar cap ionosphere, Radio Sci., 23, 513-519, 1988. 
Banks, P. M., and G. Kockarts, Aeronomy, Academic Press, New York 1973.

Berry, S. T., L. Kersley, J. Moen, and W. F. Denig, Ionospheric signatures of magnetospheric boundaries in the post-noon sector, Ann. Geophysicae, submitted, 1999.

Buchau, J., B. W. Reinisch, E. J. Weber, and J. G. Moore, Structure and dynamics of the winter polar cap F-region, Radio Sci., 18, 995-1010, 1983.

Buchau, J., E. J. Weber, D. N. Anderson, H. C. Carlson, and J. G. Moore, Ionospheric structures in the polar cap, their origin and relation to $250 \mathrm{MHz}$ scintillation, Radio Sci., 20, 325-338, 1985.

Crowley, G., Critical review of ionospheric patches and blobs, URSI Review of Radio Science 1993-1996, W. R. Stone (Ed), published for the International Union of Radio Science by the Oxford University Press, 619-648, 1996.

Decker, D. T., C. E. Valladares, R. Sheehan, S. Basu, D. N. Anderson, and R. A. Heelis, Modelling daytime F-layer patches over Sondrestrom, Radio Sci., 29, 249-268, 1994.

Foster, J. C., and J. R. Doupnik, Plasma convection in the vicinity of the dayside cleft, J. Geophys. Res., 89, 9107-9113, 1984.

Kelley, J. D., and J. F. Vickrey, F-region ionospheric structure associated with anti-sunward flow near the dayside cusp, Geophys. Res. Lett., 11, 907-911, 1984.

Lockwood, M., P. E. Sandholt, S. W. H. Cowley, and T. Oguti, Interplanetary magnetic field control of dayside auroral activity and the transfer of momentum across the dayside magnetopause, Planet. Space Sci., 37, 1347-1365, 1989.

Lockwood, M., and H. C. Carlson, Production of polar cap electron density patches by transient magnetopause reconnection, Geophys. Res. Lett., 19, 1731-1734, 1992.

Lockwood, M., S. Fuselier, A. D. M. Walker, and F. Søraas, A summary of the NATO ASI on polar cap boundary phenomena, in Polar Cap Boundary Phenomena Eds J. Moen et al., NATO Advanced Study Institute Series, Kluwer Academic Press, Dordrect, vol. 509, 415-432, 1998.

McEwan, D. J., and D. P. Harris, Occurrence patterns of F layer patches over the north magnetic pole, Radio Sci., 31, 619-628, 1996.

Moen, J., P. E. Sandholt, M. Lockwood, W. F. Denig, U. P. Løvhaug, B. Lybekk, A. Egeland, D. Opsvik, and E. FriisChristensen, Events of enhanced convection and related dayside auroral activity, J. Geophys. Res., 100, 23 917-23 934, 1995.

Moen, J., S. T. Berry, L. Kersley, and B. Lybekk, Probing discrete auroral arcs by ionospheric tomography, Ann. Geophysicae, 16, 574-582, 1998.

Moen, J., H. C. Carlson, and P. E. Sandholt, Continuous observation of cusp auroral dynamics in response to an IMF $B_{y}$ polarity change, Geophys. Res. Lett., 26, 1243-1246, 1999.
Pinnock, M., A. S. Rodger and F. T. Berkey, High-latitude F region electron concentration measurements near noon: a case study, J. Geophys. Res., 100, 7723-7729, 1995.

Rodger, A. S., M. Pinnock, J. R. Dudney, K. B. Baker and R. A. Greenwald, A new mechanism for polar patch formation, J. Geophys. Res., 99, 2335-2336, 1994.

Romick, G. J., The detection and study of the visible spectrum of aurora and airglow, SPIE Methods for Atmospheric Radiometry, 91, 63-70, 1976.

Sandholt, P. E., J. Moen, A. Rudland, D. Opsvik, W. F. Denig, and T. Hansen, Auroral event sequences at the dayside polar cap boundary for positive and negative IMF $B_{y}, J$. Geophys. Res., 98, 7737-7755, 1993.

Sandholt, P. E., C. J. Farrugia, J. Moen, Ø. Noraberg, B. Lybekk, T. Sten, and T. L. Hansen, A classification of dayside auroral forms and activities as a function of IMF orientation, J. Geophys. Res., 103, 23 325-23 345, 1998.

Schunk, R. W., L. Zhu, and J. J. Sojka, Ionospheric response to travelling convection vortices, Geophys. Res. Lett., 21, 17591762, 1994.

Sojka, J. J., M. D. Bowline, R. W. Schunk, D. T. Decker, C. E. Valladares, R. Sheehan, D. N. Anderson and R. A. Heelis, Modelling polar cap F-region patches using time-varying convection, Geophys. Res. Lett., 20, 1783-1786, 1993.

Sojka, J. J., M. D. Bowline, and R. W. Schunk, Patches in the polar ionosphere: UT and seasonal dependence, J. Geophys. Res., 99, 14 959-14 970, 1994.

Valladares, C. E., D. T. Decker, R. Sheehan, and D. N. Anderson, Modelling the formation of polar cap patches using large plasma flows, Radio Sci., 31, 573, 1996.

Walker, I. K., J. A. T. Heaton, L. Kersley, C. N. Mitchell, S. E. Pryse, and M. J. Williams, EISCAT verification in the development of ionospheric tomography, Ann. Geophysicae, 14, 1413-1421, 1996

Walker, I. K., J. Moen, C. N. Mitchell, L. Kersley, and P. E. Sandholt, Ionospheric effects of magnetopause reconnection observed using ionospheric tomography, Geophys. Res. Lett., 25, 293-296, 1998.

Weber, E. J., J. Buchau, J. G. Moore, J. R. Sharber, R. C. Livingstone, J. D. Winningham, and B. W. Reinisch, F-layer ionization patches in the polar cap, J. Geophys. Res., 89, 16831694, 1984.

Weber, E. J., J. A. Klobuchar, J. Buchau, H. C. Carlson, R. C. Livingstone, O. de la Beaujardiere, M. McCready, J. G. Moore, and G.J. Bishop, Polar cap F-layer patches: structure and dynamics, J. Geophys. Res., 91, 12 121-12 129, 1986.

Whalen, J. A., Properties of the F-layer plasma in the midday throat ridge and trough, Radio Sci., 29, 219-230,1994. 